Ann. Génét. Sél. anim., I971, 3 (3), 295-313.

\title{
THE PARTIAL REGRESSION COEFFICIENTS IN PEDIGREE EVALUATION
}

\author{
Ahmed MOSTAGEER (*) \\ Institut für Tierzucht und Haustiergenetik \\ Tievärztliche Hochschule, Linke Bahngasse Ir, Wien (Österreich)
}

\section{SUMMARY}

The method described by Mostageer (1970) for assessing the efficiency of ancestor records was used to derive the partial regression coefficients for traits expressed on both sexes and for sex-limited characters. The regular cases in which all the measurable animals in the $T$ available generations of ancestors provide information of the same size were first discussed. In sexlimited characters where the number of partial regression coefficients using $T$ generations of ancestors is equal to $2 \mathrm{~T}-1$, the method presented requires only the calculation of $\mathrm{T}-1$ factors from which all the exact regression coefficients could be computed by simple arithmetic.

A solution for the irregular cases in which the ancestors provide information of different heritabilities was also attempted. Included were also the cases in which the animal in question provides information, and those in which some of the ancestors are missing or having a number of half sib progeny. A simple and exact solution was derived that requires the calculation of a few factors from which all the regsession coefficients and the accuracy could be computed. The number of these easily calculated factors does not usually exceed half the number of sources providing information. Several worked out examples are presented.

\section{INTRODUCTION}

When the pedigree records are to be used in assessing the breeding value of an animal the number of regression coefficients to be calculated with respect to the characters measured on both sexes is equal to the number $\mathrm{T}$ of ancestor generations to be included in the index, that is, assuming that each animal gives the same size of information. When the character is measured only on one sex, say the female, the number of regression coefficients will be equal to the number of female ancestors.

In a recent paper (MOSTAGEER, I970) the author described a method for assessing the efficiency of ancestor records, based on a concept suggested by

$\left(^{*}\right)$ On leave of absence from the Faculty of Agriculture, Cairo University, Égypte. 
ROBERTSON (I959). The objective of this work is to use this method in the calculation of such regression coefficients. We shall first discuss the regular cases in which each measurable animal in the pedigree gives the same size of information and then turn to the irregular cases. Assumptions made are that the animals are not inbred, that the covariance between relatives is only additive genetic and that observations are taken as deviations from the appropriate populations means. In sex-limited characters it will be assumed that the trait is expressed on females.

\section{I. - THE REGULAR CASES}

\section{A. - Equal Information From Both Sexes}

The method described by MOSTAGEER (I970), for evaluating the efficiency of ancestor records involves the conversion of evidence on the $T$ available generations of ancestors into the equivalent $n_{\mathrm{T}}^{\prime}$ half sib progeny where :

$$
\begin{gathered}
n_{\mathrm{T}}^{\prime}=\frac{2 k h^{2}}{\mathrm{I}+\alpha \beta} \\
k=\left(4-h^{2}\right) / h^{2}, \alpha=\left(\mathrm{I}+4 h^{2}-4 h^{4}\right)^{1 / 2}, \beta=\left(y_{1}+y_{2}\right) /\left(y_{1}-y_{2}\right), \\
y_{1}=\left(3-2 h^{2}+\alpha\right)^{\mathrm{T}}, y_{2}=\left(3-2 h^{2}-\alpha\right)^{\mathrm{T}}
\end{gathered}
$$

and $h^{2}$ is the heritability. That is to say that $n_{\mathrm{T}}^{\prime}$ is the number of half sib progeny that gives the same accuracy $\left(r^{2}\right)$ of the estimate of the breeding value of the animal in question as does the information on the $T$ available generations of ancestors. To arrive at the partial regression coefficients to be applied to the performance of each animal we have first to evaluate its contribution to $n_{\mathrm{T}}^{\prime}$.

The relation from which MOSTAGEER (I970) developed the general equation for $n_{\mathrm{T}}^{\prime}$ was such that

$$
n_{\mathrm{T}}^{\prime}=\frac{n_{\mathrm{T}-1} k}{n_{\mathrm{T}-1}+2 k}=\frac{\left(n_{\mathrm{T}-1}^{\prime}+w\right) k}{n_{\mathrm{T}-1}^{\prime}+w+2 k}
$$

the contribution to $n_{\mathrm{T}}^{\prime}$ of the parents relative to that of the preceding generations being $w: n_{\mathrm{r}-1}^{\prime}$ where $w=\left(4-h^{2}\right) /\left(\mathrm{I}-h^{2}\right)$. From relation I

$$
\begin{aligned}
\frac{n_{\mathrm{T}}^{\prime}}{n_{\mathrm{T}}^{\prime}+k} & =\frac{w+n_{\mathrm{T}-1}^{\prime}}{2\left(n_{\mathrm{T}-1}^{\prime}+w+k\right)}, \text { i.e., } \\
n_{\mathrm{T}}^{\prime} & =\left(n_{\mathrm{T}}^{\prime}+k\right)\left[\frac{w}{2\left(n_{\mathrm{T}-1}^{\prime}+w+k\right)}+\frac{n_{\mathrm{T}-1}^{\prime}}{2\left(n_{\mathrm{r}-1}^{\prime}+w+k\right)}\right] \\
& =\left(n_{\mathrm{T}}^{\prime}+k\right)\left[\frac{\mathrm{I}-m_{\mathrm{r}-1}}{2}+\frac{n_{\mathrm{T}-1}}{2\left(n_{\mathrm{T}-1}^{\prime}+w+k\right)}\right]
\end{aligned}
$$

where $m_{\mathrm{T}-1}=\left(n_{\mathrm{r}-1}^{\prime}+k\right) /\left(n_{\mathrm{r}-1}^{\prime}+w+k\right) . \quad$ In this Equation (2) the parents contribute 
$\left(n_{\mathrm{T}}^{\prime}+k\right)\left(\mathrm{I}-m_{\mathrm{T}-1}\right) / 2$ half sib offspring and the rest of $n_{\mathrm{T}}^{\prime}$ represent the contribution of all the preceding generations of ancestors. Now $n_{\mathrm{T}-1}^{\prime}$ could be put as

$$
n_{\mathrm{T}^{-1}}^{\prime}=\left(n_{\mathrm{T}-1}^{\prime}+k\right)\left[\frac{\mathrm{I}-m_{\mathrm{T}-2}}{2}+\frac{n_{\mathrm{T}^{-2}}^{\prime}}{2} \frac{\left.n_{\mathrm{T}^{-2}}^{\prime}+\varphi+k\right)}{2}\right]
$$

Applying this to Equation (2)

$$
\begin{aligned}
n_{\mathrm{T}}^{\prime} & =\left(n_{\mathrm{T}}^{\prime}+k\right)\left[\frac{\mathrm{I}-m_{\mathrm{T}-1}}{2}+\frac{n_{\mathrm{T}-1}^{\prime}+k}{2\left(n_{\mathrm{T}-1}^{\prime}+w+k\right)}\left(\frac{\mathrm{I}-m_{\mathrm{T}-2}}{2}+\frac{n_{\mathrm{T}-2}^{\prime}}{2\left(n_{\mathrm{T}-2}^{\prime}+w+k\right)}\right)\right] \\
& =\left(n_{\mathrm{T}}^{\prime}+k\right)\left[\frac{\mathrm{I}-m_{\mathrm{T}-1}}{2}+\frac{m_{\mathrm{T}-1}}{2} \cdot \frac{\mathrm{I}-m_{\mathrm{T}-2}}{2}+\frac{m_{\mathrm{T}-1}}{2} \frac{n_{\mathrm{T}-2}^{\prime}}{2\left(n_{\mathrm{T}-2}^{\prime}+w-k\right)}\right]
\end{aligned}
$$

the contribution of the grandparents is then $\left(n_{\mathrm{T}}^{\prime}+k\right)\left(m_{\mathrm{T}-1} / 2\right)\left[\left(\mathrm{I}-m_{\mathrm{T}-2}\right) / 2\right]$. In general the parents' contribution to $n_{\mathrm{T}}^{\prime}$ will be $\left(n_{\mathrm{T}}^{\prime}+k\right)\left(\mathrm{I}-m_{\mathrm{T}-1}\right) / 2$ and the contribution ${ }_{\mathrm{T}} \mathrm{C}_{t}$ of generation $t$ of ancestors $(t>\mathrm{I})$ will be

$$
{ }_{\mathrm{T}} \mathrm{C}_{t}=\left(n_{\mathrm{T}}^{\prime}+k\right)(1 / 2)^{t}\left(\mathrm{I}-m_{\mathrm{T}-t}\right) \underset{i=\mathrm{T}-t+1}{\mathrm{~T}-1} m_{i}
$$

Table I contains the values of $n_{\mathrm{T}}^{\prime}$ up to 5 generations of ancestors and the limiting values of $n_{\mathrm{T}}^{\prime}$ for $\mathrm{I} 8$ different heritabilities ranging from 0.05 to 0.90 , together with the corresponding accuracies. Table 2 shows the actual contributions of the 5 generations of ancestors to $n_{5}^{\prime}$ and their values relative to ${ }_{5} \mathrm{C}_{5}$ for the same I 8 heritabilities. It is needless to stress the fact already shown by SEARLE (I963) that the inclusion of more generations of ancestors adds less and

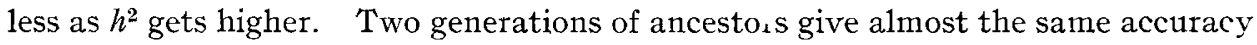
as the infinite pedigree chart when $h^{2}=0.90$. The nature of Equation 3 says also that the ratio between the contribution (to $n_{\mathrm{T}}^{\prime}$ ) of the $T-t_{1}$ generation to that of the $\mathrm{T}-t_{2}$ is always the same for the same $h^{2}$ regardless of the number $\mathrm{T}$ of the ancestors generations $\left(t_{1}\right.$ and $t_{2}$ having values from 0 to $\left.\mathrm{T}-\mathrm{I}\right)$. Thus, given the contributions ${ }_{5} \mathrm{C}_{t}$ one can calculate the $\mathrm{T}$ components of $n_{\mathrm{T}}^{\prime}$ when $\mathrm{T}$ is less thant 5 . For example, the 3 components of $n_{3}^{\prime}$ for $h^{2}=0.50$ will have the ratio I0:3:I, i.e., out of the 2.882 half sib daughters $\left(=n_{3}^{\prime}\right)$ the parents contribute Io/I4, the grandparents $3 / \mathrm{I} 4$ and the great grandparents $\mathrm{I} / \mathrm{I} 4$.

The value ${ }_{\mathrm{T}} \mathrm{C}_{t}$ of the contribution to $n_{\mathrm{T}}^{\prime}$ of the $t^{t h}$ generation of ancestors is provided equally by the $2^{t}$ ancestors of that generation, i.e., each member contributes $1 / 2^{x}$ of the ${ }_{T} C_{t}$ half sib offspring. Now we have to note that the genetic covariance between the individual's breeding value and his half sib offspring is $\sigma_{g}^{2} / 2$ (where $\sigma_{g}^{2}$ is the additive genetic variance) while that between his breeding value and any of the ancestors of generation $t$ is $(1 / 2)^{t} \sigma_{g}^{2}$. Thus we have to multiply the performance of each of the ancestors of generation $t$ by $2^{t-1}$ to get it on the same scale as the half sib progeny of the individual in question. So the weight given to the performance of each ancestor in generation $t$ will be $1 / 2{ }_{\mathrm{T}} \mathrm{C}_{t}$ (where $1 / 2$ is $\left.2^{t-1} \times 1 / 2\right)$. This is then further multiplied by the factor $2 /\left(n_{\mathrm{T}}^{\prime}+k\right)$ to produce the contribution of the ancestor's performance to the estimate of the breeding 
TABIE I

The values of $\mathrm{n}_{\mathrm{T}}^{\prime}$ and the corresponding accuracies $\left(\mathrm{r}_{\mathrm{T}}^{2}\right)$ for characters measured in both sexes

TABLEAU I

Les valeurs de $\mathrm{r}_{\mathrm{T}}^{\prime}$ avec leur précision $\left(\mathrm{r}_{\mathrm{T}}^{2}\right)$ pour dos caractères mesurés dans les deux sexes

\begin{tabular}{|c|c|c|c|c|c|c|c|c|c|c|c|c|}
\hline$h^{2}$ & $n_{1}^{\prime}$ & $n_{2}^{\prime}$ & $n_{3}^{\prime}$ & $n_{4}^{\prime}$ & $n_{5}^{\prime}$ & $n_{\infty}^{\prime}$ & $\gamma_{1}^{2}$ & $\gamma_{2}^{2}$ & $\gamma_{3}^{2}$ & $\gamma_{4}^{2}$ & $\gamma_{5}^{2}$ & $r_{\infty}^{2}$ \\
\hline 0.05 & 2.026 & 2.975 & $3.4 \times 3$ & 3.612 & $3.7 \circ 3$ & $3 \cdot 77^{8}$ & 0.025 & 0.036 & $0.04 \Upsilon$ & 0.044 & 0.045 & 0.046 \\
\hline 0.10 & 2.053 & $2.95 \mathrm{I}$ & $3 \cdot 33 \mathrm{I}$ & 3.489 & 3.555 & 3.601 & $0.05^{\circ}$ & 0.070 & 0.079 & 0.082 & 0.084 & 0.085 \\
\hline O.I 5 & $2.08 \mathrm{I}$ & 2.928 & 3.256 & $3 \cdot 3^{80}$ & 3.427 & 3.455 & 0.075 & O. 102 & o. I I 3 & o. I I 6 & O. I I 8 & O. IIG \\
\hline 0.20 & 2. I I I & 2.906 & 3.186 & 3.282 & 3.315 & $3 \cdot 33^{2}$ & 0.100 & o. I 33 & O. 144 & o. 147 & O. I 49 & o. 149 \\
\hline 0.25 & 2.143 & 2.885 & 3.122 & 3.196 & 3.219 & 3.229 & o. 125 & 0.161 & o. I 72 & o.1 76 & o. 177 & o. I 77 \\
\hline 0.30 & 2.176 & 2.865 & 3.063 & 3.119 & 3.134 & $3.14^{\circ}$ & O. I 50 & o. I 88 & o. I99 & 0.202 & 0.203 & 0.203 \\
\hline 0.35 & 2.212 & 2.846 & 3.010 & $3.05 \mathrm{I}$ & $3.06 \mathrm{I}$ & $3.06_{5}$ & o.1 75 & $0.2 \mathrm{I} 4$ & 0.224 & 0.226 & 0.227 & 0.227 \\
\hline 0.40 & $2.25^{\circ}$ & 2.829 & 2.962 & $2.99 \mathrm{I}$ & 2.998 & 3.000 & 0.200 & 0.239 & $0.24^{8}$ & 0.249 & $0.25^{\circ}$ & $0.25^{\circ}$ \\
\hline 0.45 & 2.290 & $2.8 \mathrm{I} 3$ & 2.919 & $2.94^{\circ}$ & 2.944 & 2.945 & 0.225 & 0.263 & 0.270 & 0.272 & 0.272 & 0.272 \\
\hline 0.50 & 2.333 & 2.800 & 2.882 & 2.897 & 2.899 & 2.899 & 0.250 & 0.286 & 0.292 & 0.293 & 0.293 & 0.293 \\
\hline 0.55 & 2.379 & 2.789 & $2.85 \mathrm{I}$ & $2.86 \mathrm{I}$ & 2.862 & 2.862 & 0.275 & 0.308 & 0.313 & 0.313 & 0.313 & 0.313 \\
\hline 0.60 & 2.429 & 2.782 & 2.827 & 2.833 & 2.833 & 2.833 & 0.300 & 0.329 & 0.333 & 0.333 & 0.333 & 0.333 \\
\hline 0.65 & $2.48 \mathrm{I}$ & 2.778 & 2.809 & 2.812 & $2.8 \mathrm{I} 3$ & $2.8 \mathrm{I} 3$ & 0.325 & $0.35^{\circ}$ & 0.353 & 0.353 & 0.353 & 0.353 \\
\hline 0.70 & $2.53^{8}$ & 2.779 & 2.799 & $2.80 \mathrm{I}$ & $2.80 \mathrm{r}$ & $2.80 \mathrm{I}$ & $0.35^{\circ}$ & $0.37 \mathrm{I}$ & 0.373 & 0.373 & 0.373 & 0.373 \\
\hline 0.75 & 2.600 & 2.786 & 2.797 & 2.798 & 2.798 & 2.798 & 0.375 & $0.39 \mathrm{I}$ & 0.392 & 0.392 & 0.392 & $0.39^{2}$ \\
\hline 0.80 & 2.667 & 2.800 & 2.806 & 2.806 & 2.806 & 2.806 & 0.400 & 0.412 & $0.4 \mathrm{I} 2$ & $0.4 \mathrm{I} 2$ & 0.412 & 0.4 I 2 \\
\hline 0.85 & 2.739 & 2.824 & 2.827 & 2.827 & 2.827 & 2.827 & 0.425 & 0.432 & 0.433 & 0.433 & 0.433 & 0.433 \\
\hline 0.90 & 2.8 I 8 & 2.862 & 2.862 & 2.862 & 2.862 & 2.862 & $0.45^{\circ}$ & 0.454 & 0.454 & 0.454 & 0.454 & 0.454 \\
\hline
\end{tabular}

TABLE 2

The contributions of the 5 generations of ancestors to $\mathrm{n}_{5}^{\prime}$

TABLEAU 2

La contribution des 5 générations d'ancêtres à $\mathrm{n}_{5}^{\prime}$

\begin{tabular}{|c|c|c|c|c|c|c|c|c|c|c|c|}
\hline$h^{2}$ & $n_{5}^{\prime}$ & ${ }_{5} C_{1}$ & ${ }_{0} C_{2}$ & ${ }_{5} C_{3}$ & ${ }_{5} C_{4}$ & ${ }_{5} \mathrm{C}_{5}$ & $\frac{{ }_{5} C_{5} C_{1}}{{ }_{5} C_{5}}$ & $\frac{{ }_{5} C_{5} C_{2}}{{ }_{5}}$ & $\frac{{ }_{5} C_{5} C_{3}}{{ }_{5} C_{5}^{-}}$ & $\frac{{ }_{5} C_{5} C_{4}}{C_{5}}$ & $\frac{{ }_{5} C_{5}}{{ }_{5} C_{5}}$ \\
\hline 0.05 & 3.703 & I. 98 I & 0.945 & $0.45^{2}$ & 0.218 & 0.106 & I 8.689 & 8.917 & 4.266 & 2.053 & I.000 \\
\hline 0.10 & 3.555 & I. 969 & 0.896 & 0.410 & o. 189 & 0.090 & $2 \mathrm{I} .94 \mathrm{I}$ & 9.989 & 4.568 & 2. I I I & I. .000 \\
\hline 0.15 & 3.427 & 1.962 & 0.852 & 0.372 & 0.165 & 0.076 & 25.923 & I I . 255 & 4.913 & 2.176 & 1.000 \\
\hline 0.20 & 3.315 & I. $96 \mathrm{I}$ & $0.8 \mathrm{II}$ & 0.337 & 0.143 & 0.064 & 30.863 & 12.766 & 5.313 & 2.250 & 1.000 \\
\hline 0.25 & 3.219 & І. 964 & 0.773 & 0.306 & 0.124 & 0.053 & 37.086 & 14.593 & $5.77^{8}$ & 2.333 & I.000 \\
\hline 0.30 & 3.134 & I.97I & 0.736 & 0.277 & 0.106 & 0.044 & 45.063 & 16.834 & 6.327 & 2.429 & 1.000 \\
\hline 035 & 3.061 & г. 984 & 0.702 & $0.25^{\circ}$ & $0.09 \mathrm{~J}$ & 0.036 & 55.494 & 19.629 & 6.982 & 2.538 & 1.000 \\
\hline 0.40 & $2.99^{8}$ & 2.001 & 0.668 & 0.224 & 0.077 & 0.029 & 69.457 & 23.185 & 7.778 & 2.667 & 1.000 \\
\hline 0.45 & 2.944 & 2.023 & 0.634 & 0.200 & 0.064 & 0.023 & $88.67 \mathrm{I}$ & $27.8 \mathrm{r} 2$ & 8.760 & $2.8 \mathrm{I} 8$ & 1.000 \\
\hline 0.50 & 2.899 & $2.05 \mathrm{I}$ & $0.60 \mathrm{I}$ & 0.177 & 0.053 & 0.018 & I 16.000 & 34.000 & 10.000 & 3.000 & I.000 \\
\hline 0.55 & 2.862 & 2.084 & 0.567 & 0.155 & 0.043 & 0.013 & I 56.463 & $4^{2} .554$ & II. 605 & 3.222 & 1.000 \\
\hline 0.60 & 2.833 & 2.12 .5 & $0.53 \mathrm{I}$ & 0.133 & 0.034 & 0.010 & 219.437 & 54.875 & $\mathrm{I} 3.75^{\circ} \mathrm{O}$ & 3.500 & I. .000 \\
\hline 0.65 & 2.813 & 2.174 & 0.494 & O.II 2 & 0.026 & 0.007 & 323.863 & 73.568 & I6.735 & 3.857 & I.000 \\
\hline 0.70 & $2.80 \mathrm{I}$ & 2.232 & 0.453 & 0.092 & 0.019 & 0.004 & 512.048 & I03.926 & 2 I.III & 4.333 & r. .000 \\
\hline 0.75 & 2.798 & 2.303 & 0.408 & 0.072 & 0.013 & 0.003 & 891.999 & 158.000 & 28.000 & 5.000 & 1.000 \\
\hline 0.80 & 2.806 & 2.388 & 0.356 & 0.053 & 0.008 & $0.00 \mathrm{I}$ & I.795.999 & 268.000 & 40.000 & 6.000 & 1.000 \\
\hline 0.85 & 2.827 & $2.49 \mathrm{I}$ & 0.296 & 0.035 & 0.004 & $0.00 \mathrm{I}$ & 4.578 .7 I I & 543.185 & 64.444 & 7.667 & I.000 \\
\hline 0.90 & 2.862 & 2.620 & $0.22 \mathrm{I}$ & 0.019 & 0.002 & 0.000 & I 8.196.01 2 & I. $53^{8.00 I}$ & I 30.000 & 11.000 & 1.000 \\
\hline
\end{tabular}


value of the animal in question. Thus the regression $\left(b_{t j}\right)$ applied to the performance of the ancestor $j$ at generation $t$ will be

$$
b_{t j}=\left(\frac{\mathrm{I}}{2}\right)^{t}\left(\mathrm{I}-m_{\mathrm{T}-1}\right) \underset{i=\mathrm{T}--t+1}{\mathrm{~T}-1} m_{i}
$$

The values of $m_{t}$ (up to $m_{5}$ ) and the limiting $m$ values for I 8 different heritabilities are shown in Table 3. It is clear in fact that the values of $m_{2}$ are almost the same as the corresponding limiting values of $m$, and this indicates that we need only to calculate the two values of $m_{1}$ and $m_{2}$ (beside $m_{0}$ which is $\mathrm{I}-h^{2}$ ) and to use $m_{2}$ for all values of $m$ with subscripts greater than 2 . It has to be noted in passing that if we use the mean of the ancestors at each generation $t$ then the regression coefficient $\left(b_{t}\right)$ applied will be $2^{t} b_{t j}$ or

$$
b_{t}=\left(\mathrm{I}-m_{\mathrm{T}-t}\right) \underset{i=\mathrm{T}-t+1}{\mathrm{~T}-1} m_{i}
$$

TABLE 3

The $\mathrm{m}$ values for characters measured on both sexes (*)

TABLEAU 3

Les valeurs de $\mathrm{m}$ pour les caractères mesurés dans les deux sexes

\begin{tabular}{l|l|l|l|l|l|l}
\hline$h^{\mathrm{s}}$ & $m_{1}$ & $m_{2}$ & $m_{3}$ & $m_{4}$ & $m_{5}$ & $m_{\infty}$ \\
& & & & & \\
\hline & & & & & \\
0.05 & 0.951 & 0.952 & 0.952 & 0.952 & 0.952 & 0.952 \\
0.10 & 0.905 & 0.906 & 0.907 & 0.907 & 0.908 & 0.908 \\
0.15 & 0.860 & 0.863 & 0.865 & 0.865 & 0.865 & 0.865 \\
0.20 & 0.816 & 0.822 & 0.824 & 0.824 & 0.824 & 0.825 \\
0.25 & 0.774 & 0.782 & 0.784 & 0.784 & 0.785 & 0.785 \\
0.30 & 0.733 & 0.742 & 0.744 & 0.745 & 0.745 & 0.745 \\
0.35 & 0.692 & 0.703 & 0.705 & 0.706 & 0.706 & 0.706 \\
0.40 & 0.652 & 0.663 & 0.666 & 0.667 & 0.667 & 0.667 \\
0.45 & 0.612 & 0.624 & 0.626 & 0.627 & 0.627 & 0.627 \\
0.50 & 0.571 & 0.583 & 0.585 & 0.586 & 0.586 & 0.586 \\
0.55 & 0.530 & 0.542 & 0.543 & 0.544 & 0.544 & 0.544 \\
0.60 & 0.488 & 0.498 & 0.500 & 0.500 & 0.500 & 0.500 \\
0.65 & 0.444 & 0.453 & 0.454 & 0.454 & 0.454 & 0.454 \\
0.70 & 0.397 & 0.405 & 0.406 & 0.406 & 0.406 & 0.406 \\
0.75 & 0.348 & 0.354 & 0.354 & 0.354 & 0.354 & 0.354 \\
0.80 & 0.294 & 0.298 & 0.298 & 0.298 & 0.298 & 0.298 \\
0.85 & 0.235 & 0.237 & 0.237 & 0.237 & 0.237 & 0.237 \\
0.90 & 0.168 & 0.169 & 0.169 & 0.169 & 0.169 & 0.169 \\
\hline
\end{tabular}

(*) $m_{0}=\mathrm{I}-h^{2}$.

In this case it is clear that the weight in the final index given to the mean of the $2^{t}$ ancestors of generation $t$ may be comparable to the weight given to the parents' mean. This is true for the low heritability values. For instance, the ratio between the weight given to the parents' mean to the mean of the fifth 
generation of ancestors (when $\mathrm{T}=5$ ) is $1.98: \mathrm{I} .70$ when $h^{2}=0,05$, and $\mathrm{I} .96: 0.85$ when $h^{2}=0.25$. This ratio increases to $2.30: 0.04$ when $h^{2}=0.75$.

The method of calculating the regression coefficients may better be discribed on the ancestors' map. This will be useful for further discussion. In Figure I $a$ we wish to estimate the breeding value of $Q$ using the information about the three generations of ancestors. The regression coefficients applied to each ancestor will be the product of the paths connecting it with $Q$, starting with a solid line and tracing the broken ones afterwards towards $Q$. Thus the regression coefficient applied to $\mathrm{A}$ (or any member of the third generation of ancestors) will be

$$
b_{\mathrm{A}}=\frac{\mathrm{I}-m_{0}}{2} \times \frac{m_{1}}{2} \times \frac{m_{2}}{2}
$$

that applied to $\mathrm{J}$ (or any member of the second generation) will be

$$
b_{\mathrm{J}}=\frac{\mathrm{I}-m_{1}}{2} \times \frac{m_{2}}{2}
$$

and that applied to $\mathrm{O}$ or $\mathrm{P}$ will be

$$
b_{o}=b_{p}=\frac{\mathrm{I}-m_{2}}{2} .
$$

\section{B. - Sex Limited Characters}

In sex limited characters the situation is different since each member of the $\mathrm{t}^{\text {th }}$ generation of ancestors contributes differently. Converting information on $\mathrm{T}+\mathrm{I}$ generations of ancestors into the equivalent $\mathrm{N}_{\mathrm{T}+1}$ half sib daughters MosTAGEER (I970) showed that

$$
\mathrm{N}_{\mathrm{T}^{+1}}=k \frac{2 \mathrm{~N}_{\mathrm{T}}^{2}+2 \mathrm{~N}_{\mathrm{T}}(w+k)+w k}{2 \mathrm{~N}_{\mathrm{T}}^{2}+2 \mathrm{~N}_{\mathrm{T}}(w+3 k)+w k^{2}} .
$$

This recurrent relation could be used to calculate the values of $\mathrm{N}$ for any number of ancestor generations starting with $\mathrm{N}_{0}=0.0$. The values of $\mathrm{N}_{\mathrm{T}}$ (up to $\mathrm{N}_{5}$ ) and its limiting values for the $\mathbf{I} 8$ heritabilities are shown in Table 4 together with the corresponding accuracies.

We proceed to fraction $\mathrm{N}_{\mathrm{T}}$ into its component parts. The accuracy of the estimate of breeding value of the individual in question is $\mathrm{N}_{\mathrm{T}} /\left(\mathrm{N}_{\mathrm{T}}+k\right)$ and this is the sum of the two accuracies arrived at using the $\mathrm{N}_{\mathrm{T}^{-1}}$ half sib daughters of the father equivalent to his ancestors' information, and $\mathrm{N}_{\mathrm{T}-1}+w$ half sib daughters of the mother equivalent to her own performance plus those of her ancestors. These two accuracies are

$$
\frac{\mathrm{N}_{\mathrm{T}-1}}{4\left(\mathrm{~N}_{\mathrm{T}-1}+k\right)} \text { and } \frac{\mathrm{N}_{\mathrm{T}-1}+w}{4\left(\mathrm{~N}_{\mathrm{T}-1}+w+k\right)}
$$


TABLE 4

The values of $\mathrm{N}_{\mathrm{T}}$ and the corresponding accuracies $\left(\mathrm{r}_{\mathrm{T}}^{2}\right)$ for sex-limited characters

TABIEAU 4

Les valeurs de $\mathrm{N}_{\mathrm{T}}$ avec les précisions correspondantes $\left(\mathrm{r}_{\mathrm{T}}^{2}\right)$ pour les caractères limités au sexe

\begin{tabular}{|c|c|c|c|c|c|c|c|c|c|c|c|c|}
\hline$h^{2}$ & $\mathrm{~N}_{1}$ & $\mathrm{~N}_{2}$ & $\mathrm{~N}_{3}$ & $\mathrm{~N}_{4}$ & $\mathrm{~N}_{5}$ & $\mathrm{~N}_{\infty}$ & $\gamma_{1}^{2}$ & $\gamma_{2}^{2}$ & $v_{3}^{2}$ & $r_{4}^{2}$ & $r_{5}^{2}$ & $\gamma_{\infty}^{2}$ \\
\hline 0.05 & I.OOO & I. 485 & I. 717 & I. 829 & I. 882 & I.930 & 0.012 & 0.018 & $0.02 \mathrm{I}$ & 0.023 & 0.023 & 0.024 \\
\hline 0.Io & I.000 & I. $47^{\circ}$ & I. 687 & 1. 786 & I. 832 & I. 869 & 0.025 & 0.036 & $0.04 \mathrm{I}$ & 0.044 & 0.045 & 0.046 \\
\hline O.I 5 & I.OOO & I. $45^{6}$ & I.659 & I. 747 & I. 786 & I. 8 I6 & $0.03^{8}$ & 0.054 & $0.06 \mathrm{I}$ & 0.064 & 0.065 & 0.066 \\
\hline 0.20 & I.000 & I. 443 & 1.632 & I. 7 I I & r. 745 & I. 768 & $0.05^{\circ}$ & $0.07 \mathrm{I}$ & 0.079 & 0.083 & 0.084 & 0.085 \\
\hline 0.25 & I. 000 & I. $43^{\circ}$ & I. 607 & х. 679 & I. 707 & I. 726 & 0.063 & 0.087 & 0.097 & O.IOI & 0.102 & 0.103 \\
\hline 0.30 & I. & I. 418 & I. 584 & I. 648 & 1. 673 & г. 688 & 0.075 & o.103 & o.I I 4 & O.II 8 & O.II9 & 0.120 \\
\hline 0.35 & I. 000 & I. 407 & I. 563 & I. $62 \mathrm{I}$ & 1.642 & I. 654 & 0.087 & O.II9 & o.I30 & o.I35 & o.136 & o.137 \\
\hline 0.40 & I.OOO & I. 397 & I. 543 & I. 596 & I. $6 \mathrm{I}_{4}$ & 1.624 & 0.100 & o.134 & 0.146 & $0.15^{\mathrm{I}}$ & o.I $5^{2}$ & o. I 53 \\
\hline 0.45 & I. 000 & I. 388 & I. 525 & I. 573 & $x .589$ & I. 597 & o. I I 3 & o.I $5^{\circ}$ & 0.162 & o.x66 & o.168 & 0.168 \\
\hline 0.50 & I.ooo & I. 379 & I. 509 & I. $55^{2}$ & I.566 & I. 573 & O.I 25 & o.I65 & o.I77 & O.I 82 & o.I 83 & o.I 84 \\
\hline 0.55 & I.OOO & $\mathrm{I} \cdot 37 \mathrm{I}$ & I. 495 & I. 534 & I. 546 & I. $55^{2}$ & o.I 37 & o. I 79 & 0.192 & o.197 & o.198 & o.198 \\
\hline 0.60 & I.OOO & I. 365 & 1.482 & I. 518 & I. 529 & I. 534 & o.I $5^{\circ}$ & o.194 & 0.207 & $0.2 \mathrm{II}$ & $0.2 \mathrm{I} 3$ & 0.213 \\
\hline 0.65 & I.OOO & I.359 & $\mathrm{I} .47 \mathrm{I}$ & 1.505 & I. 5 I 4 & I. $51^{8}$ & o. I63 & 0.209 & 0.222 & 0.226 & 0.227 & 0.228 \\
\hline 0.70 & I. 000 & $\mathrm{x} .355$ & I. 462 & I. 493 & I. 502 & I.506 & o. I 75 & 0.223 & 0.237 & $0.24 \mathrm{I}$ & 0.242 & 0.242 \\
\hline 0.75 & I.00o & $\mathrm{r} \cdot 35^{2}$ & I. 456 & I. 485 & I. 493 & I. 496 & o.I 88 & 0.238 & $0.25^{\mathrm{I}}$ & 0.255 & 0.256 & 0.257 \\
\hline 0.80 & 1.000 & I. $35^{\circ}$ & r. $45^{2}$ & ×. 479 & I. 486 & I. 489 & 0.200 & $0.25^{2}$ & 0.266 & 0.270 & $0.27 \mathrm{I}$ & $0.27 \mathrm{I}$ \\
\hline 0.85 & I.000 & I. $35^{\circ}$ & I. $45^{\circ}$ & I. 476 & I. 483 & I. 486 & $0.2 \times 3$ & 0.267 & $0.28 \mathrm{I}$ & 0.285 & 0.286 & 0.286 \\
\hline 0.90 & I. 000 & I. 353 & I. $45^{\mathrm{I}}$ & I. 477 & I. 484 & I. 486 & 0.225 & 0.282 & 0.296 & 0.300 & 0.301 & $0.30 \mathrm{I}$ \\
\hline
\end{tabular}

respectively. On the maternal side the ratio between the contribution of the mother's performance to that of her ancestors is $w: \mathrm{N}_{\mathrm{T}-1}$. Thus of the $\mathrm{N}_{\mathrm{T}} /\left(\mathrm{N}_{\mathrm{T}}+k\right)$ the mother comtributes

$$
\frac{w}{4\left(\mathrm{~N}_{\mathrm{T}-1}+w+k\right)}=\left(\mathrm{I}-m_{\mathrm{T}-1}\right) / 4
$$

and the rest of the pedigree (maternal and paternal) contributes

$$
\frac{\mathrm{I}}{4}\left(\frac{\mathrm{N}_{\mathrm{T}^{-1}}}{\mathrm{~N}_{\mathrm{T}-1}+w+k}+\frac{\mathrm{N}_{\mathrm{T}-1}}{\mathrm{~N}_{\mathrm{T}-\mathbf{1}}+k}\right)=\frac{\mathrm{I}}{4}\left(\frac{\mathrm{N}_{\mathrm{T}-1}}{\mathrm{~N}_{\mathrm{T}-1}+k}\right)\left(\mathrm{I}+m_{\mathrm{T}-1}\right) .
$$

Note that the contribution of the paternal pedigree relative to the maternal pedigree is $\mathrm{I}: m_{\mathrm{T}-1}$. Now the value of $\frac{\mathrm{N}_{\mathrm{T}-1}}{\mathrm{~N}_{\mathrm{T}^{-1}-1}+k}$ could in turn be subdivided in a manner similar to that used for $\mathrm{N}_{\mathrm{T}} /\left(\mathrm{N}_{\mathrm{T}}+k\right)$. This operation repeated will give the general form for the contribution ${ }_{T} \mathrm{C}_{t}$ of the $t^{\text {th }}$ generation (where $t>\mathrm{I}$ ):

$$
{ }_{\mathrm{T}} \mathrm{C}_{t}=\left(\frac{\mathrm{I}}{2}\right)^{2 t}\left(\mathrm{~N}_{\mathrm{T}}+k\right)\left(\mathrm{I}-m_{\mathrm{T}-t}\right) \underset{i=\mathrm{T}-t+1}{\prod^{\mathrm{T}}-\mathrm{I}}\left(\mathrm{I}+m_{i}\right)
$$

Thus if we have for instance 3 generations of ancestors the mother's contribution to $\mathrm{N}_{3}$ will be $a\left(\mathrm{I}-m_{2}\right) / 4$, that of the two grandmothers will be $a\left(\mathrm{I}-m_{1}\right)$ 
$\left(\mathrm{x}+m_{2}\right) / \mathrm{I} 6$, and the share of the great grandmothers will be $a\left(\mathrm{I}-m_{0}\right)\left(\mathrm{I}+m_{1}\right)$ $\left(\mathrm{r}+m_{2}\right) / 64$, where $a=\mathrm{N}_{3}+k$.

Table 5 shows the contributions $\left({ }_{5} \mathrm{C}_{t}\right)$ of the five generations of ancestors to $\mathrm{N}_{5}$ for the I8 heritabilities, and its values relative to $\mathrm{C}_{5}$. This table as well as Table 4 show that the approach to the limiting value of $\mathrm{N}$ or $r^{2}$ is slow in sex limited characters and that the inclusion of more ancestor generations will be more effective. It may be worth noting that the values of $\mathrm{N}_{\infty}$ are less than the comparable $n_{1}^{\prime}$ in characters measured in both sexes.

TABLE 5

The contributions of the 5 generations of ancestors to $\mathrm{N}_{5}$

TABLEAU 5

Contributions des 5 générations d'ancêtres à $\mathrm{N}_{5}$

\begin{tabular}{|c|c|c|c|c|c|c|c|c|c|c|c|}
\hline$h^{2}$ & $N_{5}$ & ${ }_{5} C_{1}$ & ${ }_{5} C_{2}$ & ${ }_{5} \mathrm{C}_{3}$ & ${ }_{5} \mathrm{C}_{4}$ & ${ }_{5} C_{5}$ & $\frac{{ }_{5} C_{1}}{{ }_{5} C_{5}}$ & $\frac{{ }_{5} C_{2}}{{ }_{5} C_{5}}$ & $\frac{{ }_{5} \mathrm{C}_{3}}{{ }_{5} \mathrm{C}_{5}}$ & $\frac{{ }_{5} \mathrm{C}_{4}}{{ }_{5} \mathrm{C}_{5}}$ & $\frac{{ }_{5} C_{5}}{{ }_{5} C_{5}}$ \\
\hline 0.05 & I. 882 & 0.989 & 0.483 & $0.23^{6}$ & O.II 6 & 0.057 & 17.293 & 8.446 & $4 . \mathrm{I} 3 \mathrm{I}$ & 2.026 & 1.000 \\
\hline 0.10 & 1.832 & 0.980 & 0.468 & 0.224 & 0.108 & $0.05^{2}$ & 18.735 & 8.937 & 4.274 & 2.055 & I.000 \\
\hline 0.15 & 1.786 & 0.973 & 0.453 & 0.212 & 0.100 & 0.048 & 20.353 & $9 \cdot 4^{8 !}$ & $4.43^{2}$ & 2.087 & I. .000 \\
\hline 0.20 & I. 745 & 0.968 & $0.44^{\circ}$ & $0.20 \mathrm{I}$ & 0.093 & 0.044 & 22.177 & 10.086 & 4.605 & 2.123 & I.00o \\
\hline 0.25 & 1.707 & 0.963 & 0.428 & o.I9I & 0.086 & 0.040 & 24.247 & 10.76I & 4.797 & 2.162 & I. .000 \\
\hline 0.30 & х.673 & $0.96 \mathrm{r}$ & $0.4 I^{16}$ & $0.18 \mathrm{I}$ & 0.080 & 0.036 & 26.610 & II. 5 I 8 & 5.010 & 2.206 & I.000 \\
\hline 0.35 & $1.64^{2}$ & 0.959 & 0.405 & 0.172 & 0.074 & 0.033 & 29.329 & I 2.374 & 5.247 & 2.254 & I.000 \\
\hline 0.40 & I.614 & 0.959 & 0.394 & 0.163 & 0.068 & $0.03^{\circ}$ & 32.482 & I 3.347 & $5.5 \mathrm{I} 2$ & 2.308 & x.000 \\
\hline 0.45 & I. 589 & $0.96 \mathrm{I}$ & 0.384 & 0.154 & 0.063 & 0.027 & $3^{6.1} 7^{2}$ & 14.462 & $5.8 \mathrm{II}$ & 2.368 & I.000 \\
\hline 0.50 & I. 566 & 0.964 & 0.375 & 0.146 & 0.058 & 0.024 & 40.532 & I 5.749 & 6.149 & 2.435 & I. .000 \\
\hline 0.55 & I. $54^{6}$ & 0.969 & 0.365 & o.1 38 & 0.053 & $0.02 \mathrm{I}$ & 45.743 & 17.249 & 6.535 & 2.510 & I.000 \\
\hline 0.60 & 1.529 & 0.975 & $0.35^{6}$ & $0.13 \mathrm{I}$ & 0.049 & 0.019 & $52.05 \mathrm{I}$ & 19.017 & 6.979 & 2.595 & I.000 \\
\hline 0.65 & 1.514 & 0.983 & 0.347 & 0.123 & 0.044 & 0.016 & 59.797 & $2 \mathrm{I} .126$ & & 2.692 & 1.000 \\
\hline 0.70 & 1.502 & 0.993 & 0.339 & o.II 6 & 0.040 & 0.014 & 69.469 & 23.675 & 8.098 & 2.803 & I.000 \\
\hline 0.75 & I. 493 & I. .006 & $0.33^{\circ}$ & o. 108 & 0.036 & 0.012 & $8 \mathbf{1} .779$ & 26.807 & 8.815 & $2.93^{\circ}$ & 1.000 \\
\hline 0.80 & I. 486 & 1.022 & 0.321 & o.IOI & 0.032 & 0.010 & 97.806 & 30.728 & 9.680 & 3.077 & 1.000 \\
\hline 0.85 & I. 483 & $\mathrm{I} .04 \mathrm{I}$ & $0.3^{12}$ & 0.094 & 0.028 & 0.009 & I I 9. & 35.747 & 10.739 & $3.25^{\circ}$ & I. .000 \\
\hline 0.90 & 1.484 & 1.063 & 0.302 & 0.086 & 0.025 & 0.007 & $14^{8.867}$ & 42.346 & 12.064 & 3.454 & 1.00 \\
\hline
\end{tabular}

The value of ${ }_{\mathrm{T}} \mathrm{C}_{t}$ (where $t>\mathrm{I}$ ) is not divided equally between the $2^{t-1}$ ancestors of generation $t$, since, as shown above, the contribution of the ancestors of the father of any individual is higher than that of his mother's ancestors.

In fact the value ${ }_{T} C_{t}$ is divided between the $2^{t-1}$ contributors by the factors resulting from expanding the term ${ }^{T-1} \quad\left(I+m_{i}\right)$ in a way such that of each term $\mathrm{T}-t+1$

of $\left(\mathrm{I}+m_{i}\right) \mathrm{I}$ is used if the ancestor's descendant at generation $\mathrm{T}-i$ is a male, and $m_{i}$ if it is a female.

The contribution of each ancestor thus defined, again we have to multiply each performance by the factor $2^{t-1}$ to put it on the same scale of the individual's half sib daughters. We then can apply the factor $2 /\left(\mathrm{N}_{\mathrm{T}}+k\right)$ to get the partial 


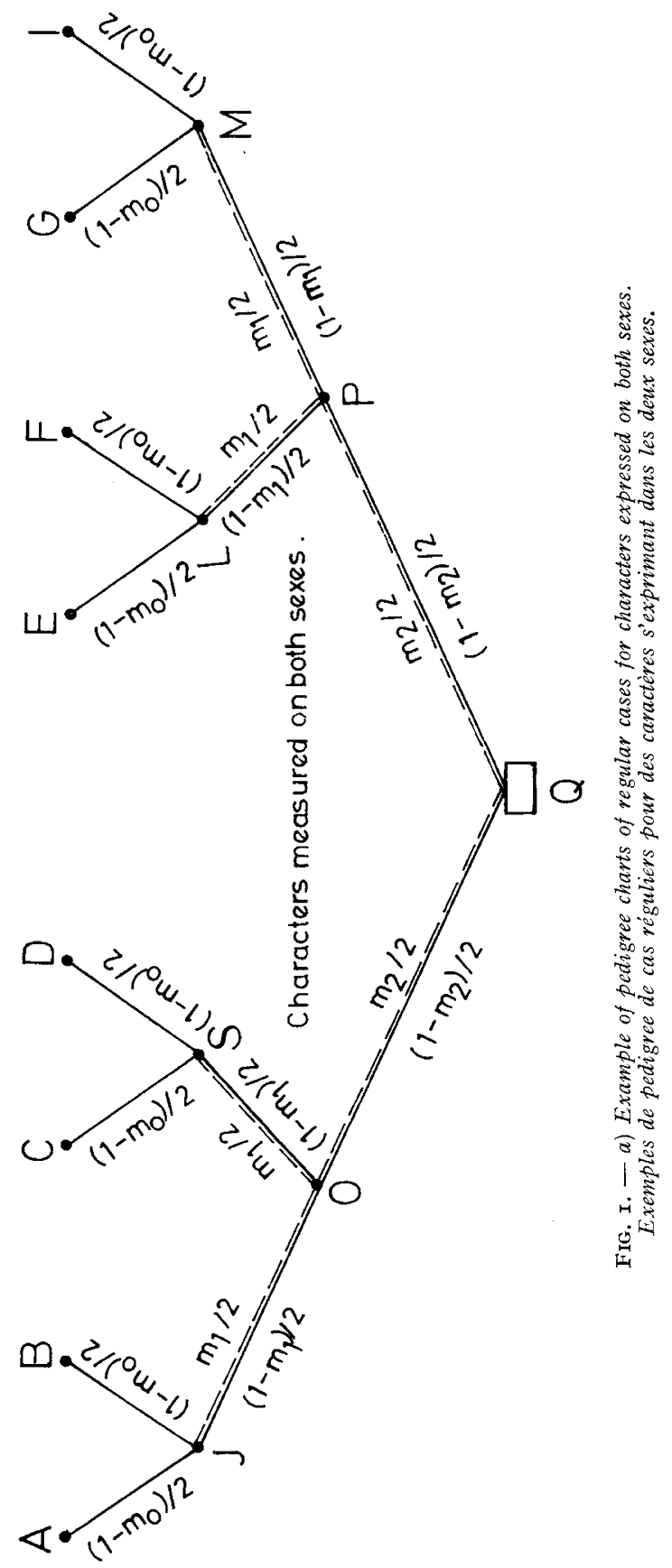


304

A. MOSTAGEER

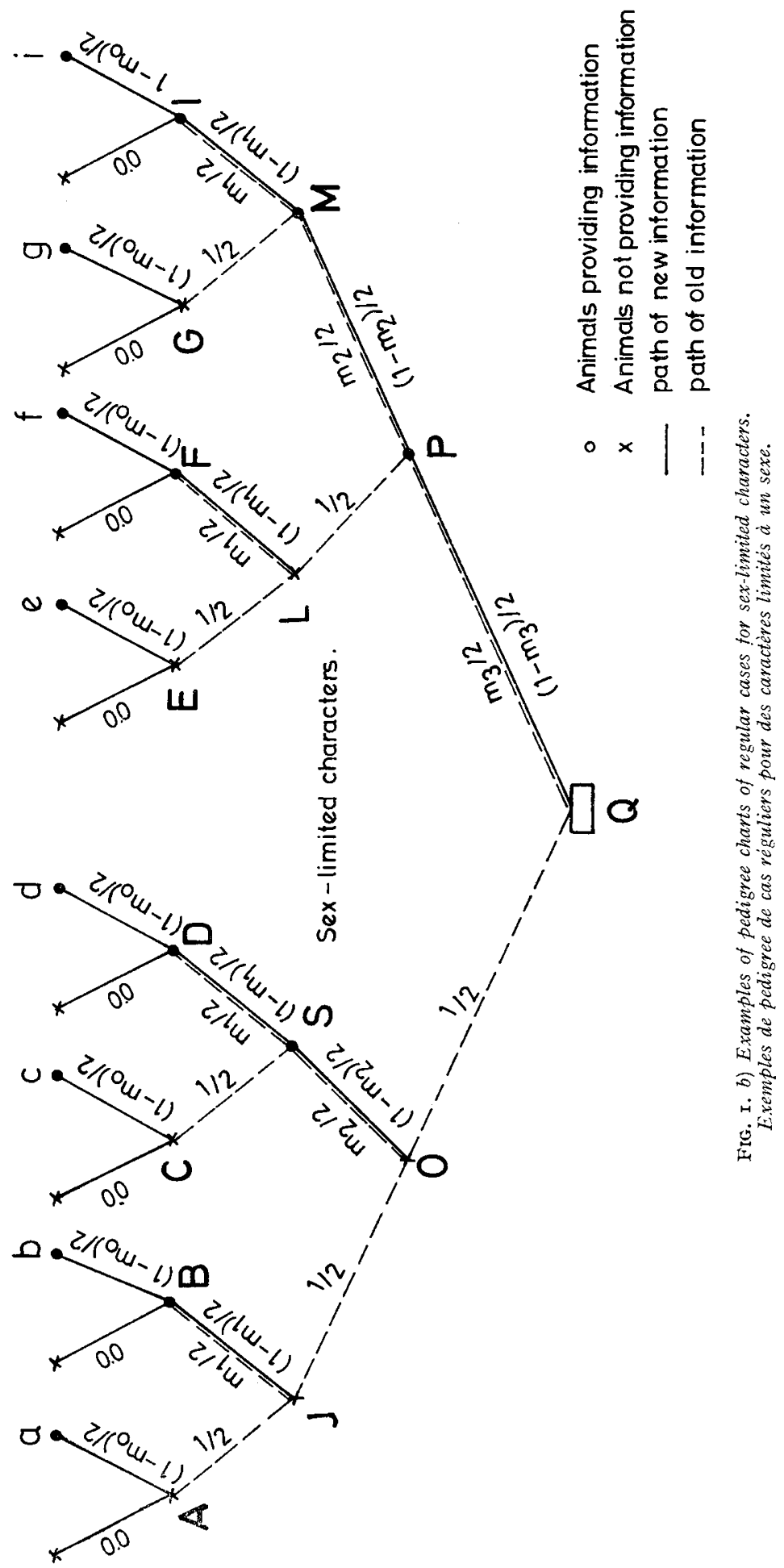


regression coefficient for the performance of each ancestor. Thus the partial regression coefficients applied to the $2^{t-1}$ ancestors of generation $t$ could be obtained by expanding the term

$$
\left(\frac{\mathrm{I}}{2}\right)^{t}\left(\mathrm{I}-m_{\mathrm{T}-\mathrm{t}}\right) \underset{\mathrm{T}-t+1}{\mathrm{~T}-\mathrm{I}}\left(\mathrm{I}+m_{i}\right)
$$

by the manner described for dividing ${ }_{T} C_{t}$.

The simplicity of this method in calculating the partial regression coefficients may better be visualised on drawing the pedigree chart. Again $m_{2}$ (or $m_{3}$ ) may be used for $m$ values of higher subscripts (see Table 6).

TABLE 6

The $\mathrm{m}$ values for sex-limited chavacters (*)

TABLEAU 6

Les valeurs de $\mathrm{m}$ pour les caractères limités au sexe (*)

\begin{tabular}{|c|c|c|c|c|c|c|}
\hline$h^{2}$ & $m_{1}$ & $m_{2}$ & $m_{3}$ & $m_{4}$ & $m_{5}$ & $m_{\infty}$ \\
\hline 0.05 & $0.95 \mathrm{I}$ & $0.95 \mathrm{I}$ & $0.95 I$ & $0.95 \mathrm{I}$ & $0.95 \mathrm{I}$ & $0.95 \mathrm{r}$ \\
\hline 0.10 & 0.902 & 0.903 & 0.904 & 0.904 & $0.90_{4}$ & 0.904 \\
\hline O.I 5 & 0.855 & 0.857 & 0.858 & $0.85^{8}$ & $0.85^{8}$ & 0.859 \\
\hline 0.20 & 0.808 & $0.8 \mathrm{II}$ & $0.8 \mathrm{I} 3$ & $0.8 \mathrm{I} 3$ & 0.814 & $0.8 \mathrm{I}_{4}$ \\
\hline 0.25 & 0.762 & 0.767 & 0.769 & 0.769 & 0.770 & $0.77^{\circ}$ \\
\hline 0.30 & 0.7 I 6 & 0.722 & 0.725 & 0.726 & 0.726 & 0.726 \\
\hline 0.35 & $0.67 \mathrm{I}$ & 0.678 & $0.68 \mathrm{I}$ & 0.682 & 0.682 & 0.683 \\
\hline $0.4^{\circ}$ & 0.625 & 0.634 & 0.637 & 0.638 & 0.639 & 0.369 \\
\hline 0.45 & 0.579 & 0.590 & 0.593 & 0.594 & 0.595 & 0.595 \\
\hline 0.50 & 0.533 & 0.545 & 0.549 & $0.55^{\circ}$ & $0.55^{\circ}$ & $0.55 \mathrm{I}$ \\
\hline 0.55 & $0.4^{87}$ & 0.499 & 0.503 & 0.505 & 0.505 & 0.505 \\
\hline 0.60 & $0.44^{\circ}$ & 0.453 & 0.457 & $0.45^{8}$ & $0.45^{8}$ & 0.459 \\
\hline 0.65 & $0.39 \mathrm{r}$ & 0.405 & 0.409 & $0.4 \mathrm{IO}$ & 0.4 I I & $0.4 \mathrm{I} \mathrm{I}$ \\
\hline 0.70 & 0.342 & $0.35^{6}$ & 0.360 & $0.36 \mathrm{r}$ & $0.36 \mathrm{I}$ & $0.36 \mathrm{I}$ \\
\hline 0.75 & $0.29 \mathrm{I}$ & 0.304 & 0.308 & 0.309 & 0.309 & 0.310 \\
\hline 0.80 & $0.23^{8}$ & $0.25 \mathrm{I}$ & 0.254 & 0.255 & 0.255 & 0.255 \\
\hline 0.85 & o.1 83 & o I94 & o.I97 & 0. 198 & 0.198 & $0.19^{8}$ \\
\hline 0.90 & 0.125 & o.r34 & o.1 36 & o. 137 & o.137 & O.I 37 \\
\hline
\end{tabular}

(*) $m_{0}=\mathbf{I}-h^{2}$.

In Figure $\mathrm{I} b$, the partial regression coefficients applied to the performances of each ancestor will be the product of the paths connecting it with the animal in question $(Q)$ starting with a " solid " line and tracing the broken lines afterwards. Thus, for example, the regression coefficients applied to $a, c, \mathrm{I}$ and $\mathrm{P}$ are

$$
\begin{aligned}
& b_{a}=\left(\frac{\mathrm{I}-m_{0}}{2}\right)\left(\frac{\mathrm{I}}{2}\right)\left(\frac{\mathrm{I}}{2}\right)\left(\frac{\mathrm{I}}{2}\right) \\
& b_{c}=\left(\frac{\mathrm{I}-m_{0}}{2}\right)\left(\frac{\mathrm{I}}{2}\right)\left(\frac{m_{2}}{2}\right)\left(\frac{\mathrm{I}}{2}\right)
\end{aligned}
$$




$$
\begin{aligned}
& b_{\mathrm{I}}=\left(\frac{\mathrm{I}-m_{1}}{2}\right)\left(\frac{m_{2}}{2}\right)\left(\frac{m_{3}}{2}\right) \\
& b_{p}=\left(\frac{\mathrm{I}-m_{3}}{2}\right)
\end{aligned}
$$

It is obvious that we need only to calculate one $m$-value for each ancestor generation included in the index over the first generation $\left(\mathrm{I}-m_{0}=h^{2}\right)$.

The method could be used of course if all the ancestors in the pedigree have a certain fixed number of 1ecords. In such case, values of $m$ relevant to $h_{d}^{2}$ are to be used instead of those for $h^{2}$ (where $h_{d}^{2}=\frac{d h^{2}}{\mathrm{I}+(d-\mathrm{I}) p}, d=$ the number of records, and $p=$ the repeatability of the character). Since the values of the partial regression coefficients of ancestors on the paternal side could be calculated independently from those on the maternal side, the method described does not require the same number of ancestor generations in both parental sides. Suppose, for instance, that we know the performances of $\mathrm{P}$ and $\mathrm{M}$ only on the mother side, and all the ancestors shown in graph $I b$ for the paternal side. The regression coefficients applied to the female ancestors of the father will be the same as calculated before, but on the mother side we have the following regression coefficients :

$$
\begin{aligned}
& b_{\mathrm{MI}}=\left(\frac{\mathrm{I}-m_{0}}{2}\right)\left(\frac{m_{1}}{2}\right) \\
& b_{p}=\left(\frac{\mathrm{I}-m_{1}}{2}\right) .
\end{aligned}
$$

In other words, the earliest generation in each of the parental sides should start with the path $\left(\frac{x-m_{0}}{2}\right)$. It may be noted also that ancestors of the maternal side need not have the same number of records as those on the paternal side for this method to work, so long as each side has a fixed number. Of course all these modifications apply also to the characters expressed in both sexes.

\section{II. - IRREGUIAAR CASES}

The regular cases now described, we can turn to the cases in which the ancestors provide information of different heritabilities. Included will also be the cases of missing ancestors, of ancestors having some recorded half sib progeny or full sib progeny from individuals outside the pedigree, and of the individual in question providing information on himself or his half- or full sib progeny. (By heritability here is meant the squared correlation).

The previous discussion has shown that the ratio between the factor by which an individual releases its information to that by which it releases its ancestors' is equal to $\frac{I-m}{m}$. This of course will hold true when animals in the pedigree 
provide information of different heritabilities. It is also clear that the $m$ value stemming from an individual provides a summary of his information and of that of all his recorded ancestors. The problem then is to relate a new $m$ value $\left(m_{j}\right)$ stemming from an individual $(j)$ to the two $m$ values $\left(m_{a}\right.$ and $\left.m_{b}\right)$ connecting it with its parents $a$ and $b$. We shall start with the situation in which the individual $j$ as well as his parents $a$ and $b$ provide information.

A simplifying device for the pedigree diagram may be suggested: When the individual in question provides new information, we can add to the diagram a pair of paths connecting this information with the " breeding value " in which we are interested, one path of the value of $m_{j}$ for " old " information and the other $\left(\mathrm{I}-m_{j}\right)$ for the new information.

The accuracy of the estimate of breeding value of the individual in question could of course be obtained by multiplying by $1 / 2$ all the paths in the pedigree diagram except $\left(\mathrm{I}-m_{j}\right)$ and $m_{j}$, and summing all the factors connecting the breeding value with all the ancestors, those factors to be calculated the same way as described in obtaining the regression coefficients. However, since

$$
r_{j}^{2}=\frac{w_{j}+n_{j}}{w_{j}+n_{j}+k_{j}}
$$

where $n_{j}$ is the number of half sib progeny equivalent to the ancestors' information, $k_{j}$ and $w_{j}$ are the $k$ and $w$ values calculated using the heritability of the individual's information $\left(h_{j}^{2}\right)$, then

$$
r_{j}^{2}=\mathrm{I}-\frac{\mathrm{I}-m_{j}}{x_{j}}
$$

where $x_{j}=\frac{w_{j}}{k_{j}}=\frac{h_{j}^{2}}{\mathrm{I}-h_{j}^{2}}$.

When $j$ does not provide information, the accuracy of the estimate of his breeding value $\left(\mathrm{R}_{j}^{2}\right)$ will be equal to $\mathrm{I} / 4$ the sum of the two accuracies of the breeding values of his two parents, or

$$
\mathrm{R}_{j}^{2}=\frac{\mathrm{I}}{4}\left(2-\frac{\mathrm{I}-m_{a}}{x_{a}}-\frac{\mathrm{I}-m_{b}}{x_{b}}\right)
$$

$x_{a}$ and $x_{b}$ being calculated using the heritabilities of $a$ and $b$ information. The value of $\mathrm{R}_{j}^{2}$ is of course equal to

$$
\mathrm{R}_{j}^{2}=\frac{n_{j}}{n_{j}+k_{j}}
$$

since $n_{j}$ represents the number of half sib offspring equivalent to the information provided by $\mathrm{j}$ 's ancestors. Equating these two values of $\mathrm{R}_{j}^{2}$ we get

$$
n_{j}=k_{j} \frac{2-\frac{\mathrm{I}-m_{a}}{x_{a}}-\frac{\mathrm{I}-m_{b}}{x_{b}}}{2+\frac{\mathrm{I}-m_{a}}{x_{a}}+\frac{\mathrm{I}-m_{b}}{x_{b}}}
$$


and since $\frac{m_{j}}{\mathrm{I}-m_{j}}$ is equal to $\frac{n_{j}+k_{j}}{w_{j}^{\prime}}$, then

$$
m_{j}=\frac{4}{4+x_{j}\left(2+\frac{\mathrm{I}-m_{a}}{x_{a}}+\frac{\mathrm{I}-m_{b}}{x_{b}}\right)}
$$

When an individual receives information from a parent (say, $a$ ) whose ancestors are not included in the index, the value of $\left(\mathrm{I}-m_{a}\right) / x_{a}$ will be equal to $\mathrm{I}-h_{a}^{2}$ and when the " $a$ " branch of ancestors does not provide any information, $h_{a}^{2}$ is then taken as 0.0 , and the value of $\left(\mathbf{I}-m_{a}\right) / x_{a}$ is then equal to I. If a parent does not provide any information over what is provided by his ancestors, i.e., if he passes his ancestors' information by a factor of $1 / 2$, then it could be shown that the appropriate value of $(\mathrm{I}-m) / x$ in Equation $\mathrm{IO}$ is equal to $(\mathbf{I}-\mathbf{H})$, where $\mathrm{H}$ is the sum of the values of $(I-m)$ in this branch of ancestors, connected to $j$ (the individual in question) only by paths of $1 / 2$, each value of which multiplied by $(1 / 4)^{g}$, where $g$ is the number of generations separating the particular $(I-m)$ value from $j$. This method of course will yield the $m$ values for the regular cases discussed above.

This method of calculating the regression coefficients will cover all the relevant cases described by OSBORNE (I957), JARDINE (I958), LE ROY (I958), Young (I96I), FEWSON (I964), LE ROY (I964), RASCh and HERRENDÖRFER (Ig68) and Flock and Haussmann (1970). In fact many of the cases described by these authors could be solved by the rather simpler method shown above for the regular cases. The following are a few examples to illustrate the application of this method.

\section{Examples}

(I) The breeding value of $j$ to be estimated (Fig. $2, a) . h^{2}$ is taken as I $/ 4$ and the repeatability $p$ as $1 / 2$. The heritability of $d$ records will be $d /(2+2 d)$. Clearly we need only to calculate one $m$ value $\left(m_{j}\right)$. Applying Equation ro:

$$
m_{j}=\frac{4}{4+\frac{2}{3}\left(2+\left(\mathrm{I}-\frac{67}{768}\right)+\mathrm{I}\right)}=\frac{4608}{76 \mathrm{I} 3}=.605
$$

where $\frac{2}{3}=h_{j}^{2} /\left(\mathrm{I}-h_{j}^{2}\right)=\frac{2}{5} / \frac{3}{5},\left(\mathrm{I}-m_{b}\right) / x_{b}$ is set equal to I since the $b$ branch does not provide information, and

$$
\frac{67}{768}=\mathrm{H}=\left(\frac{\mathrm{I}}{4}\right)^{3} h_{\mathrm{E}}^{2}+\left(\frac{\mathrm{I}}{4}\right)^{2} h_{\mathrm{F}}^{2}+\left(\frac{\mathrm{I}}{4}\right)^{1} h_{\mathrm{G}}^{2} .
$$

Thus the regression coefficients are:

$$
b_{\mathrm{E}}=\left(\frac{\mathrm{I}}{4}\right) \frac{\mathrm{I}}{2} \times \frac{\mathrm{I}}{2} \times \frac{\mathrm{I}}{2} \times \frac{\mathrm{I}}{2} \times m_{j}=.009
$$


USE OF REGRESSION IN PEDIGREE EVALUATION

$$
\begin{aligned}
b_{\mathrm{F}}=\left(\frac{\mathrm{I}}{3}\right) \frac{\mathrm{I}}{2} \times \frac{\mathrm{I}}{2} \times \frac{\mathrm{I}}{2} \times m_{j} & =.025 \\
b_{\mathrm{a}} & =\left(\frac{\mathrm{I}}{4}\right) \frac{\mathrm{I}}{2} \times \frac{\mathrm{I}}{2} \times m_{j}=.038 \\
b_{j} & =\mathrm{I}-m_{j} \quad=.395
\end{aligned}
$$

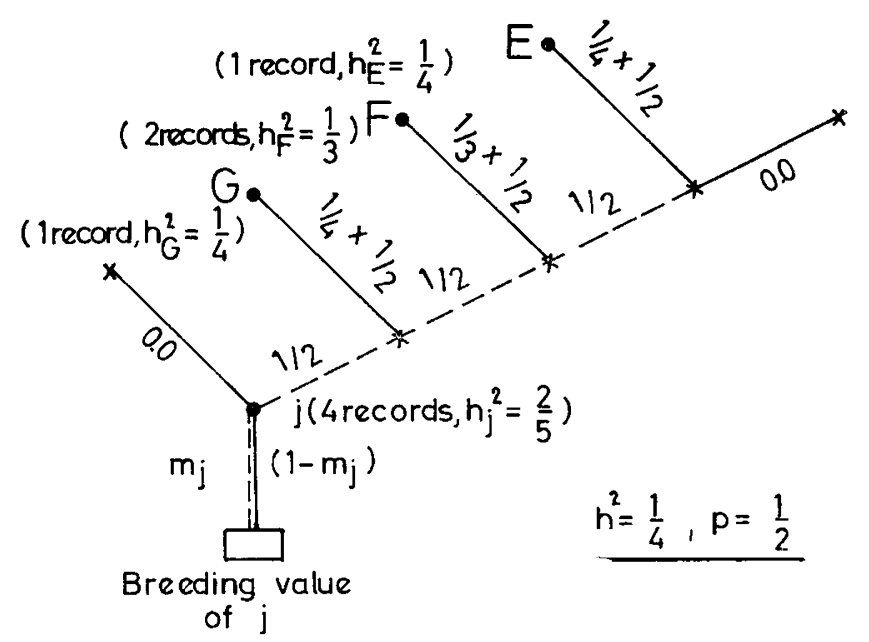

(a)

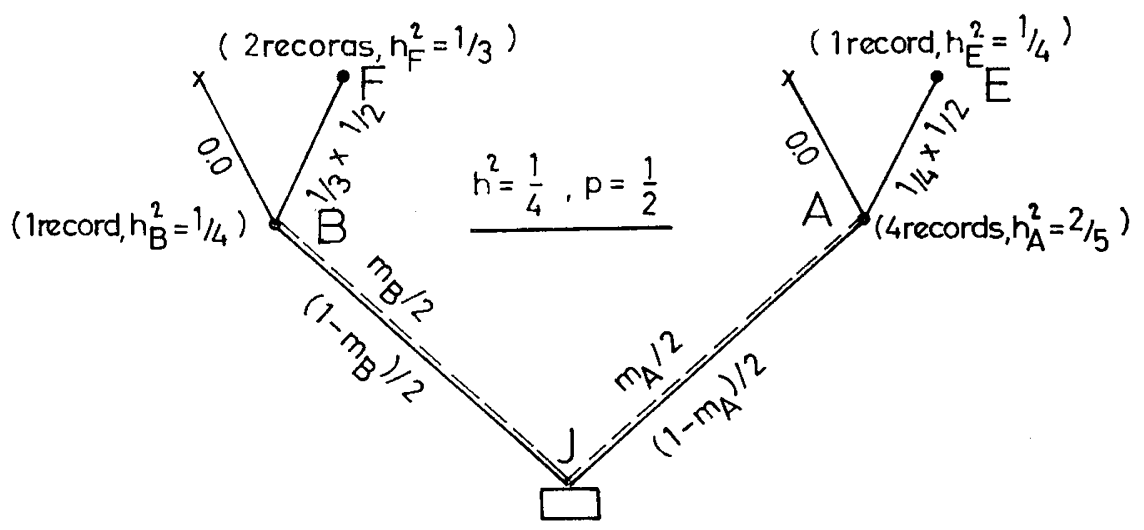

(b)

\section{Breeding value}

FIG. 2. The pedigree diagrams of the irregular cases used in the numerical examples Pedigrees de cas irréguliers utilisés dans les exemples numériques 

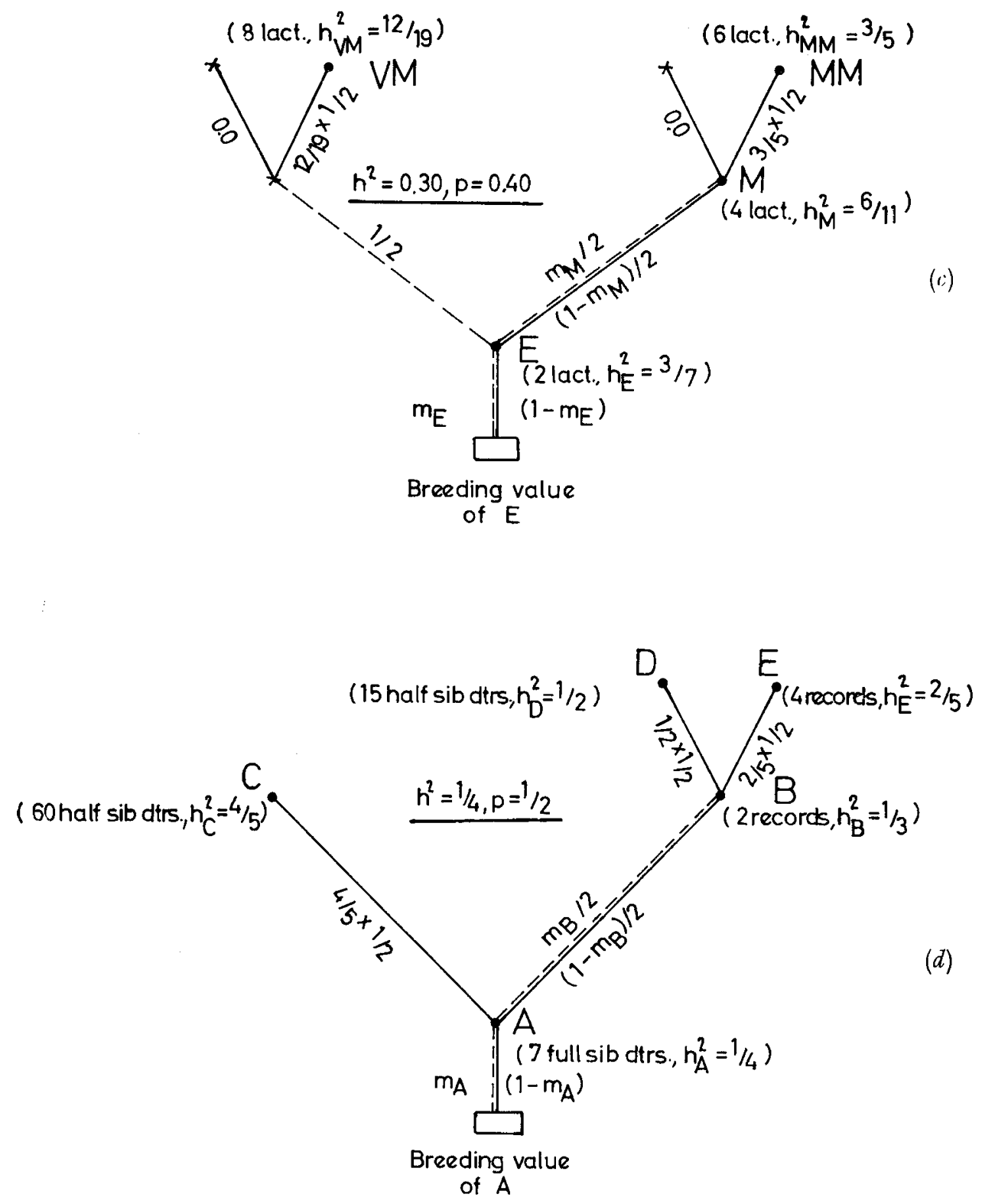

FIG. 2 (suite). - The pedigree diagrams of the irregular cases used in the numerical examples Pedigrees de cas irréguliers utilisés dans les exemples numériques

The accuracy of the estimate (applying Equation 7) will be

$$
r_{j}^{2}=\mathrm{I}-\frac{3 / 5}{2 / 5}\left(\mathrm{I}-m_{j}\right)=.408
$$


(2) The breeding value of $\mathrm{J}$ to be estimated (Fig. $2, b$ ). J does not provide information. We need to calculate two $m$ values $\left(m_{\mathrm{A}}\right.$ and $\left.m_{\mathrm{B}}\right)\left(h^{2}=.25\right.$ and $\mathrm{p}=.50)$ :

$$
\begin{aligned}
& m_{\mathrm{A}}=\frac{4}{4+\frac{2}{3}\left(2+\frac{3}{4}+\mathrm{I}\right)}=\frac{8}{\mathrm{I} 3} \\
& m_{\mathrm{B}}=\frac{4}{4+\frac{\mathrm{I}}{3}\left(2+\frac{2}{3}+\mathrm{I}\right)}=\frac{36}{47}
\end{aligned}
$$

Thus:

$$
\begin{aligned}
& b_{\mathrm{E}}=\left(\frac{\mathrm{I}}{4}\right) \frac{\mathrm{I}}{2} \times \frac{m_{\mathrm{A}}}{2}=\frac{\mathrm{I}}{26} \\
& b_{\mathrm{F}}=\left(\frac{\mathrm{I}}{3}\right) \frac{\mathrm{I}}{2} \times \frac{m_{\mathrm{B}}}{2}=\frac{3}{47} \\
& b_{\mathrm{A}}=\left(\mathrm{I}-m_{\mathrm{A}}\right) / 2=\frac{5}{26} \\
& b_{\mathrm{B}}=\left(\mathrm{I}-m_{\mathrm{B}}\right) / 2=\frac{\mathrm{II}}{94}
\end{aligned}
$$

The accuracy is to be estimated using Equation 8:

$$
r_{J}^{2}=\frac{\mathrm{I}}{4}\left(2-\frac{5}{\mathrm{I} 3} \times \frac{3}{2}-\frac{\mathrm{II}}{47} \times 3\right)=. \mathrm{I} 8 \mathrm{O}
$$

(3) This example is taken from $\mathrm{LE}_{\mathrm{E}} \mathrm{ROY}$ (I958). $h^{2}=.30$ and $p=.40$. The breeding value of $\mathrm{E}$ to be estimated (Fig. 2,c). This example requires the calculation of $2 \mathrm{~m}$ values:

$$
\begin{aligned}
& m_{\mathrm{M}}=\frac{4}{4+\frac{6}{5}\left(2+\mathrm{I}+\frac{2}{5}\right)}=.495 \\
& m_{\mathrm{E}}=\frac{4}{4+\frac{3}{4}\left(2+\frac{.505 \times 5}{6}+\frac{\mathrm{I} 6}{\mathrm{I} 9}\right)}=.62 \mathrm{I}
\end{aligned}
$$

Thus:

$$
\begin{array}{ll}
b_{\mathrm{MM}}=\left(\frac{3}{5}\right) \frac{\mathrm{I}}{2} \times \frac{.495}{2} \times .62 \mathrm{I} & =.046 \\
b_{\mathrm{vM}}=\left(\frac{\mathrm{I}}{\mathrm{I}}\right) \frac{\mathrm{I}}{2} \times \frac{\mathrm{I}}{2} \times .62 \mathrm{I} & =.098 \\
b_{\mathrm{M}}=\left(\mathrm{I}-m_{\mathrm{M}}\right) \frac{\mathrm{I}}{2} \times .62 \mathrm{I} & =. \mathrm{I} 57
\end{array}
$$




$$
\begin{array}{ll}
b_{\mathrm{E}}=\mathrm{I}-.62 \mathrm{I} & =.379 \\
r_{\mathrm{E}}=\mathrm{I}-\frac{.379 \times 4}{3} & =.495
\end{array}
$$

(4) The estimate of the breeding value of $\mathrm{A}$ is required (Fig. 2, d). The father (C) has 60 half sib daughters and the grandfather D has $15 . h^{2}$ is taken as .25 and the repeatability as .50 . The heritability to be attached to $\mathrm{C}$ or $\mathrm{D}$ is $\frac{n}{n+k}, n$ being the number of half sib offspring. The mean performance of the daughters has to be doubled to get it on the same scale of their father's breeding value. Thus the information on $\mathrm{C}$ may be taken as if a character of the $h^{2}$ of $\frac{4}{5}\left(=\frac{60}{60+I 5}\right)$ was measured on himself, and his performance was double the mean of his 60 daughters. The information supplied by the 7 full sib daughters of A is equivalent to 5 half sib daughters (MOSTAGEER, I969). This provides an $h^{2}$ of $I / 4$ and a performance of double the mean of the daughters. (This method of converting the full sib daughters into half sib daughters is useful when the individual has several groups of full sib daughters.)

$$
\begin{aligned}
& m_{\mathrm{B}}=\frac{4}{4+\frac{\mathrm{I}}{2}\left(2+\frac{\mathrm{I}}{2}+\frac{2 / 5}{2 / 3}\right)}=\frac{80}{\mathrm{III}}=.72 \mathrm{I} \\
& m_{\mathrm{A}}=\frac{4}{4+\frac{\mathrm{I}}{3}\left(2+\frac{\mathrm{I}}{5}+\frac{3 \mathrm{I} / \mathrm{III}}{\mathrm{I} / 2}\right)}=.8 \mathrm{I} 3
\end{aligned}
$$

Thus:

$$
\begin{array}{ll}
b_{\mathrm{E}}=\left(\frac{2}{5}\right) \frac{\mathrm{I}}{2} \times \frac{.72 \mathrm{I}}{2} \times .8 \mathrm{I} 3 & =.059 \\
b_{\mathrm{D}}=2 \times\left(\frac{\mathrm{I}}{2}\right) \frac{\mathrm{I}}{2} \times \frac{.72 \mathrm{I}}{2} \times .8 \mathrm{I} 3 & =. \mathrm{I} 47 \\
b_{\mathrm{B}}=\frac{.279}{2} \times .8 \mathrm{I} 3 & =. \mathrm{II} 4 \\
b_{\mathrm{C}}=2 \times\left(\frac{4}{5}\right) \frac{\mathrm{I}}{2} \times .8 \mathrm{I} 3 & =.650 \\
b_{\mathrm{A}}=2 \times(. \mathrm{I} 87) & =.374 \\
r_{\mathrm{A}}^{2}=\mathrm{I}-(. \mathrm{I} 87 \times 3) & =.439
\end{array}
$$




\title{
ACKNOWLEDGEMENT
}

The writer wishes to express his thanks to Professor Dr. Franz Pirchner for his comments on the manuscript and for providing access to the electronic computer.

\author{
RÉSUMÉ
}

\section{LES COEFFICIENTS DE RÉGRESSION PARTIELLE DANS LES ESTIMATIONS SUR ORIGINE}

La méthode décrite par Mostageer (1970) pour estimer l'efficacité des performances des ascendantes est utilisée pour calculer les coefficients de régression partielle correspondant aux caractères extériorisés par les deux sexes et à ceux qui n'apparaissent que chez un sexe. Le premier cas étudié est celui où tous les ancêtres jusqu'à la Tme génération, fournissent une information de mème valeur. Lorsque les caractères ne sont extériorisés que par l'un des sexes, les coefficients de régression partielle, au nombre de $2 \mathrm{~T}-1$, peuvent être simplement déduits de $\mathrm{T}-1$, facteur seulement.

Une solution est donnée également lorsque les informations apportées par les ascendantes ont des héritabilités différentes. Sont aussi traités les cas où l'animal étudié apporte lui-même une information, celui où certains ascendants sont inconnus et celui où on en connaît une descendance de $1 / 2$ frère $1 / 2$ sneur. La solution exacte et simple fournie exige le calcul d'un petit nombre seulement de facteurs dont on peut déduire les coefficients de régression et la précision. Le nombre de ces facteurs facilement calculables n'excède jamais la moitié du nombre des sources d'information.

Plusieurs exemples d'application sont proposés au lecteur.

\section{REFERENCES}

FEwson D. P., I964. Untersuchungen über die Effektivität verschiedener Selektionsmassnahmen unter besonderer Beriicksichtigung der züchterischen Verbesserung der Milchmenge und des Fettgehaltes beim Rind. Z. Tierz. Zücht Biol., 79, гог-г6r.

Flock D. K., Haussmann H., r970. Tabellen für die Zuchtwertschätzung bei landwirtschaftlichen Nutztieren. Ausschluss genetisch-statistischer Methoden in der Tierzucht der deutschen Gesellschaft für Zïchtungskunde pp. I05.

JARDINE R., I958. Animal breeding and the estimation of genetic value. Heredity, 12, 499-5II.

L,E Roy H. L., I958. Die Abstammungsbewertung. Z. Tierz. Zücht Biol., 71, 328-378.

LE ROY H. L., I964. Die verallgemeinerte Abstammungsbewertung. Z. Tierz. ZüchtBiol., 79, 303-309.

Mostageer A., 1969. The use of information on mates in estimating breeding values. Z. Tierz. Zücht Biol., 86, 42-51.

Mostageer A., I97o. The usefulness of pedigree information in animal selection with special reference to dairy cattle. Z. Tierz. Zïcht Biol., 87, 56-6r.

OSBORNE R., 1957. The use of sire and dam averages in increasing the efficiency of selective breeding in hierarchical mating systems. Heredity, 11, 93-I 6 .

RASCH D., HERRENDÖRFER G., r968. Statistische Untersuchungen zur Selektion auf quantitative Merkmale. Biom. Z., 10, I73-r8r.

Robertson A., I959. A simple method of pedigree evaluation in dairy cattle. Anim. Prod., 1, I67-I74. SEARLE S. R., I963. The efficiency of ancestor records in animal selection. Heredity 18, 35I-360.

Young S. S. Y., I96r. The use of sire's and dam's records in animal selection. Heredity, 16, 9r-roz. 